M. L., 13, a native of Perthshire, was admitted to my ward october 27th, 1903. She was a well-grown girl, and had three brothers and one sister, but none of these nor any discoverable relative is or was similarly affected. According to her mother's account, the disease commenced when she was her mother's account, the disease commenced when she was These went away for a time and came back. Next the portion of the skin now implicated became dry and discoloured, especially the palms and soles.

The scalp was free from scales, the hair plentiful and auburn in hue. The face showed nothing abnormal. The palms exhibited elevated areas of enormously thickened epidermis, quite $\frac{1}{4}$ in. deep and sharply defined. Between these areas were spaces or fissures floored by integument apparently natural. The same condition extended about 1 in. up the front of the wrist, but the backs of the hands presented nothing unusual. At the bend of each elbow there was an oval area, 3 in. long by 2 in. broad, accurately marked off from the surrounding healthy skin. This area was black in tint, and had an aspect like very coarse plush, consisting of epidermic spicules closely set and standing up vertically. To the finger these gave the impression of a coarse, rough, shorthaired brush. Fine long hairs were interspersed between the spicules. The same condition was seen at the margins of the axillae and within the axillae, except in the very centre, where the skin was smooth over the space of an inch. The nipples and 'their areolae, the flanks, the front of the abdomen but avoiding the umbilicus, the groins but not the pubic region the patellar area, the popliteal space, the ankles and roots of the toes were covered with the same black, filiform, epidermic growth. The soles were overlapped with hard, dry, epidermic plates, more than $\frac{1}{4}$ in. thick, which broke away in places. Some of the nails were distorted and rough.

The treatment adopted for the body and limbs was the same as in the previous case, and need not be reiterated, but in order to afford every opportunity of thinning down the hypertrophied epidermis of the palms and soles, so far at least as to render it possible that when again at home there might be reasonable chance of its being kept in a fairly pliant condition she was retained in the ward till April 17th, 1904. To reduce the tylosis various methods were tried in succession. Thus the parts were enveloped in boric starch poultices for weeks, and attempts made to remove the soddened layers by scraping them with a sharp spoon, or by grinding them down with pumice stone. But no great progress was accomplished in this way. The epidermis, no doubt, was softened and rendered oedematous in this way, but at the same time it grew tender, while it did not become markedly thinner. Next, the continuous application of a resorcin plaster muslin was essayed but this failed to occasion exfoliation, and after a prolonged test was abandoned. On the whole, the application of $\epsilon$ mol keleet as a thick watery paste, under an impervious dressing of jaconet, proved the most successful of all. After six weeks of this combined with friction with pumice stone, the thickness of the epidermis was very considerably reduced, movement was free, while the troublesome fissures had grown much fewer. On the soles there was now only one distinct crack across the root of the toes, the rest of the surface was fairly soft, smooth, and pliant. The palms were, however, in hardly so satisfactory a condition, there were still many and wide fissures present. Some of these showed at their base an almost normal epithelial surface, others were narrow and painful, apt to bleed if stretched. Yet the hands could now be closed and opened after a fashion, which was quite impossible when she was admitted. For a short time thyroid tablets were given by Dr. Norman Walker during my absence. No perceptible effect was produced on the ichthyosis, while there was general discomplort and increased rapidity of the pulse. Its further employment was therefore given up.

Everywhere on the body the ichthyosis was reduced to a minimum. There was no trace remaining on the nipples or their areolae, where it had been so pronounced. The groins and the popliteal spaces presented a natural aspect. At the margins of the axillae, in the bend of the elbows and in front of the neck, there was nothing more than a slight yellowish, ridgy undulation. All the thready, papillary warty growths had disappeared, though the surface still had a pale yellow tint. The hairs seen at the bend of the elbow were still visible. The skin of the backs of the hands was now specially thin and transparent, so that the veins shone conspicuousl through. She had become much fatter, and the skin and scalp hair were healthy and well nourished. Though the application of resorcin had been continued throughout, there never was any sign of absorption, shown by darkening of the urine. When she was discharged, her parents were directed to wash her daily with resorcin and salicylic soap all over, hands and feet included, and to rub the palms and soles with pumice stone, after drying.

Whatever may be the hidden cause of ichthyosis, it is evident that it must be regarded as an exaggerated development of epidermis, or, as Thibierge well expresses it, "a hyperkeratosis with atrophy of the deep lavers of the rete mucosum." It is doubtful if the quasi-inflammatory appearances described by Unna and Tommasoli are not accidental rather than inherent characteristics. Its essence consists, then, in undue retention of the corneous layer, and not, as Brocq, usually so accurate, describes it, "as a disease characterized by incessant epidermic desquamation." 2 In fact exfoliation is in abeyance. As to the cause of this retention we are quite in the dark, antenatal pathology has so far failed to elucidate it, and the attractive epitrichium theory of Dumesnil and Bowen is negatived by the last case related, since in the very situations where according to it separation of the epitrichium occurs earliest, as in the axilla, and hence the ichthyosis should be absent, hyperkeratosis was especially noticeable.

In treatment, therefore, our efforts must be directed to promote and ensure regular systematic exfoliation of the unduly adherent and effete horny cells. There are various substances which have the power of thinning down, artificially, the epidermis. Sulphur is one, but if used it not only adds to the abnormal aridity, but is apt to set up exudative and even inflammatory processes. Salicylic acid, too, in the dilute form in which alone it can be prudently employed over extensive areas and for a length of time, fails to accomplish what is needed. Resorcin, however, not only favours continual desquamation but tends to leave the subjacent surface polished and pliant; hence its use is specially indicated. Combined with an oily base it dries up or is rubbed off. Glycerine from its hygroscopic properties is the excipient par excellence, but applied alone is rather irritating. In union with starch it forms a bland, persistent, soothing, and softening medium, and, as has been seen, while in all cases so used it proves eminently beneficial, if its application is begun early enough and steadily persevered in, it can effect what must be regarded as a cure.

At the same time, with all its qualifications, the resorcinized glycerine of starch alone would not enable us to get continuously rid of the ever newly-forming accretions of epidermis. We must therefore have recourse to a medicated soap, and a superfatted one with which resorcin and salicylic acid are incorporated-that which is so valuable in shortening the desquamative stage in scarlet fever - has proved adequate, and prepares the way for the subsequent glycerinization.

Internal remedies are of little use in ichthyosis. The only one which aids us at all is cod-liver oil administered in small doses at night. Pilocarpine is inoperative in early treatment, unnecessary in later.

$$
\begin{aligned}
& \text { REFERENCES. } \\
& 1 \text { La Pratique Dermatologique. Paris, 1901. Tome ii, p. 840. }{ }^{2} \text { Traité }
\end{aligned}
$$
Elementaire de Dermatologie Pratique, Paris, 1907, Tome ii, p. 686.

\section{THE TREATMENT OF RODENT ULCER BY} ZINC IONS.

\section{A Lecture delivered at the Medical Graddates'} Collegre and Polyclinic.

BY H. LEWIS JONES, M.D., F.R.C.P., MEDICAL OFFICER IN CHARGE OF THE ELECTRICAL DEPARTMENT,
ST. BARTHOLOMEW'S HOSPITAL.

I HAVE much pleasure in bringing forward the subject of the treatment of rodent ulcer by zinc ions, because it is not only new but good. Of late years the treatment of rodent ulcer has been robbed of many of its difficulties by the discovery of the effects of $x$ rays and of radium. Both of these agencies give good results when applied to rodent ulcer; in fact they cure the disease in a large proportion of cases, yet they have certain drawbacks. For instance, in the case of radium, the material is extremely costly; and in the case of the $x$ rays, an elaborate apparatus is required, and there is also a certain amount of risk attending both procedures, as their effect upon the tissues is difficult to control. The method which I am about to describe is a simple one; it can be carried out with an ordinary portable battery, and the results which it yields are quick and good.

The process is based upon the principle of the introduction of zinc, or rather of ions of zinc, into the tissues of the ulcer by means of a continuous current. The transportation of the zinc ions into the tissue of the affected part seems to exercise a profound influence upon rodent ulcer, causing it to assume the appearence of an ordinary simple sore, and, in many instances, to heal up in about a fortnight after a single application.

Before proceeding further, I shall ask you to look at a patient who had a rodent ulcer of the nose for five years. She gave the history that the sore had never healed since its com- 
mencement, but had slowly extended and this is the usual history in these cases. On April 23rd, 1906, she was sent to me by $\mathrm{Mr}$. B swlby, and I made an application, using a solution of zinc sulphate for a period of twelve minutes. When she was seen on May 15th, three weeks later, the ulcer was found to be completely healed, and it has remained so ever since.

That case represents the ordinary behaviour of a rodent ulcer after its treatment by the introduction of zinc, and here I should state that most of the cases which I have treated by the zinc method have been small rodent ulcers of less than an inch in diameter. The history of the method is as follows :

In 1903, Dr. S. Leduc, Professor of Physics in the Medical School of Nantes, published a note ${ }^{1}$ on the cicatrization of a rodent ulcer at the angle of the nose which had lasted five years, after a single application of electroysis with zinc. In a short paper of abjut thirty lines he described his treatment of a case of rodent ulcer by means of an application to the ulcer of electrolysis with a 1 per cent. solution of zinc chloride on a pad of absorbent wool, using a zinc rod and the positive pole. The effect was to drive the zinc ions into the tissues of the ulcer, and he states that after a fortnight the ulcer had heale 1 except for a minute spot at one corner, on which he repeated the treatment, with the result that the whole was eompletely cured.

In the following year I had an opportunity of trying the method in a case of rodent ulcer on the cheek of an elderly woman, and used a solution of zinc chloride with a zinc positive pole, passing a current for ten or twelve minutes, as described by Leduc. A fortnight later the rodent ulcer was completely healed. I have seen that patient from time to time since, and although it is now more than two years since the application there has been no sign of any recurrence.

Naturally, I was very much interested in that result, and have since treated a number of other cases in the same way with success, so that in a lecture given before the Hunterian Society in October, 1905, I was able to record 7 cases. I have now done 19 cases, and with the exception of 5 , which I shall shortly relate, the results have been successful. Therefore I feel justified in saying that the method is good.

In regard to the physics of the process, the term "zinc ions " signifies the condition of the atoms of the zinc when one of its salts is dissolved in a solvent like distilled water. For instance, zinc sulphate in solution in water exists in a partially dissociated form, the salt being partly split up into atoms of zinc carrying a positive charge of electricity, zinc ions, and an equal number of molecules of $\mathrm{SO}_{4}$, or sulphuric ions, having a negative charge. When conduction of electricity takes place in such a solution, or in the tissues of the human body, it takes place only by the conveyance of the electrical charges by an actual movement or migration of the ions.

In the case of zinc sulphate, the zinc ions with their positive charges move towards the negative pole, and conversely the negatively charged sulphuric ions move towards the positive pole, so that the electrolysis of a solution of zinc sulphate tends to cause a concentration of sulphuric acid at the positive pole, and of zinc at the negative. This movement of the ions is made use of to introduce them into the body, and, if at the positive pole there is lint or cotton-wool imbibed with a solution of a zinc salt, and if the negative pole be placed on some other convenient part of the patient, the zinc will begin to move inwards on its way towards the negative pole directly the current begins to flow, and, although in the time of an ordinary application it cannot reach the negative pole, yet at least it starts upon its journey, so that in an application which lasts ten minutes some of the zinc ions will penetrate to a depth of one, two, or more millimetres into the tissues beneath the positive electrode, and that may be enough to enable it to permeate the diseased area if it be a superficial one.

Rodent ulcer, therefore, being superficial, at least in its early stages, and in general not having any great thickness, lends itself well to medication in this way. By the electrolytic process the zinc ions can be driven into the cells of the part in a way which is impossible with lotions or ointments. With these but little of the drug penetrates at all, and that which is absorbed is probably carried off by the lymph channels, and distributed over the system in a short time. But when ions penetrate under electrical action they enter not only into the lymph spaces but also into the protoplasm of each cell which they reach and their influence is therefore a more intimate one, and it seems as though the introduced drug remained in situ for a considerable time. Leduc has noted, for instance, that the local effect of adrenalin introduced electrically can be seen to persist much longer than after an ordinary topical application of that drug.

The sulphuric ions of the zinc sulphate solution do not. migrate inwards from the positive pole but move towards the electrode, and if the electrode is made of zinc they combine with the metal to form more zinc sulphate, and thus the supply of fresh ions of the metal is maintained, and the quantity of zinc sulphate present in the moistened pad remains much the same at the end of the application as at the beginning.

As the conduction of electricity in a solution is effected solely by the movement of ions, each carrying its fixed charge of electricity, the current shown by the galvanometer enables one to calculate the amount of zinc or other metal introduced into the patient in a given time. The electro-chemical equivalent of the metal, multiplied by the magnitude of current used and by the duration of the time of the application, gives in the case of zinc the following result for a current of 10 milliamperes for ten minutes, namely, a little over $2 \mathrm{mg}$., and although this does not appear a large quantity it is effective because concentrated at the place where it is wanted.

In using electrolytic medication it is important to remember which ions will move inwards from the positive pole and which from the negative, in order to know which electrode to apply to the affected area. In general, the ions of the metals and of the alkaloids are electro-positive, and can only be introduced by the positive pole; while an acid such as salicylic or chromic acid, must be introduced from the other direction, namely, from a solution of the corresponding salt in contact with the negative pole.

The apparatus required for the treatment of rodent ulcer by zinc ions is extremely simple. An ordinary medical continuous current battery, with a galvanometer, a pair of wires, a flat pad for completing the circuit at the negative pole, and a rod or other electrode of zinc attached to the positive pole, completes the outfit. The zinc must be covered with three or four layers of lint, which serve as a reservoir to hold the zinc solution, a 2 per cent. solution of the sulphate bcing very suitable. The zinc should be freshly cleaned' or amalgamated, and the solution should be made with distilled water. It is as well not to touch the zinc electrode or its covers with the fingers unnecessarily, because every touch imparts a trace of sodium chloride from the skin, and tends to reduce the efficiency of the process a little by bringing in some foreign ions. The circuit is completed through the usual pad electrode applied to any convenient part of the patient, the zinc electrode of suitable size is held upon the rodent ulcer, and the current is slowly turned on until a current of 5 , or 8 , or 10 milliampères is reached, according to the size of the electrode used. Leduc has advised that a suitable magnitude of current to use is 2 or 3 milliamperes of current for each square centimetre of the positive electrode, and, in general, patients can bear this concentration of current without complaining. The sensation produced is a burning one, not unlike that of a mustard plaster. In patients who are sensitive it may be convenient to introduce a little cocaine beforehand. When the surface is raw the cocaine solution can be directly applied on a tuft of cotton-wool left in contact with the ulcer for a few minutes. When there is no raw surface the drug can be helped to penetrate electrolytically from the positive pole if, before using the zinc solution, a tuft of wool moistened with cocaine solution is applied to the surface of the rodent ulcer, and the current passed in with the zinc electrode, exactly as for the introduction of the zinc. The preliminary use of cocaine permits of the use of a somewhat stronger current. It is necessary to use a pure solution of cocaine, and not a solution containing sodium chloride or any other salt. A neutral salt is sometimes present in the tablets of cocaine prepared for hypodermic use, but pure solutions can be obtained in a convenient. form in sealed tubes, each containing a few drops, from druggists (for example, "Sterules" of Martindale), and $\mathbf{I}$ have found these very convenient.

It is important to mention the difficulties which mas be encountered, because one learns more from these than 
from the easy cases. The difficulties in connexion with this treatment depend mainly upon the character of the surface presented by the rodent ulcer. They differ a good deal in this respect. Some of them have a moist surface, and some of them are dry and scabbed over. Many have a formation of small pearly nodules round their margin, and there may be a subcutaneous area of infiltration rather larger than the actual ulcer. Owing to these inequalities of surface they may receive the zinc unequally, one part of the rodent ulcer receiving the greater part of the current, and another part not receiving enough. In general, it is rather more difficult to introduce the zinc effectively into the margin than into the centre. Again, some rodent ulcers have a smooth, red, waxlike surface, and are not ulcerated. These require a longer application, and time is gained by using a needle of zinc, and puncturing the surface with it. In that way, too, any semi-solid tubercle or nodule can be attacked successfully, either at the first sitting or after the whole affected area has been treated by means of the zinc rod and the lint moistened with the zinc solution as already described.

Other cases which are difficult are those which have been operated upon by $x$ rays or by the knife, and have relapsed, for they have a tendency to recur at several points around the original site, and also to invade the subcutaneous tissue.

If they have a thickness greater than two or three millimetres, it is difficult, in a reasonable time, to drive the zinc ions inwards to a sufficient depth to influence the deeper parts, unless a zinc needle is used. The advantage of using a needle is that time is saved, for if one can push the zinc needle into the depth of the part to be destroyed, the migration of the ions into the surrounding layers is accelerated, and this is a great advantage, because the rate of movement of the zinc ions is slow.

I now have under treatment a patient whose rodent ulcer has proved to be very difficult to treat. It was a recurrent case, and had once been caused to disappear by $x$ rays. The central part of it was smooth, raised, pink, and waxlike; it had a number of pearl-like tubercles round it, and it was situated close to the inner canthus of the right eye, which led to difficulties owing to the entry of the solution into the patient's eye causing pain. The nodules were therefore attacked one by one with a zinc needle, each being pierce 1 , and a current of 1 milliampère passed into it for a minute. They have now all disappeared, but there. still remains a thickened area on the adjoining part of the noзe, which is being attacked in the same way, and is on the high road to recovery.

I will now review the results so far obtained in my cases. I have treated 19 cases in all, and 6 of these have healed completely. after one introduction of the zinc ions : 3 have required two applications, and 5 have required three. Five others have not yet been finished, or have been unsuccessful. One other case, lost sight of after a single application, is not included, though I think from its nature that it was probably a success.

In theory, the treatment of rodent ulcer by zinc ions is a treatment by a single application, and when a repetition is noeded it is because the operator has failed to introduce the zinc suffic e.stly into the whole area and depth of the affected region. This may be the result of timidity or error of judgement, or it may be by reason of some condition of the individual case, as has already been indicated, as, for instance, where parts of the rodent ulcer receive a full dose while other parts do not. Under these circumstances it may be more advantageous to be content to treat the main part of a rodent ulcer at the first sitting, and to leave certain portions to be attacked subsequently, when the part first done has healed over and become covered by sound skin. The effect of an application continues for some time. A month may be allowed to pass before a repetition, and careful observation will sometimes show a progressive change for the better during the whole of that time, or even longer. Thus, in one of my cases, done on September 13th, 1905, a note was made on November 17th that a small nodule persisted on the lower edge of the healed scar, but when the case was seen again in December this had disappeared spontaneously, and there has been no relapse since.

The 5 cases which are unfinished or unsuccessful may now be considered. One has already been referred to in considering the advantages of using a zinc needle for certain conditions. Another is a case of relapse after $x$-ray treatment, and presents an irregular ring of infected points upon the right ala nasi all round the old scar. Under treatment these are being dealt with one by one, and the patient has made progress, though there is still a good deal to do. It has been treated partly by needling and partly by general applications to the whole surface with the moistened pad. The third case is now probably finished, but it has given trouble through the appearance during the treatment of a new subcutaneous nodule at the edge of the scar. Its appearance has been peculiar, suggestive of an ordinary sebaceous cyst, or of a small knot of scar tissue, and it has shown no tendency to ulceration for nearly a year, but the patient is nervous, and is anxious to be rid of all appearance of disease. Recently I needled the nodule with a zinc point, but have not succeeded in obliterating it entirely. The fourth case was one closely resembling the first of this series. It was a relapse after $x$-ray treatment, with several foci of disease, and its situation on the side of the nose, very close to the eye, rendered efficient electrolysis difficult. Two applications were made and each was followed by improvement, though the medical attendant considered that the rodent ulcer subsequently grew worse after the applications, but the treatment was abandoned, as the patient was apprehensive of bad effects upon the vision, owing to the proximity of the electrode to the eye, and to the retinal stimulation by the current.

The fifth case is one of extensive relapsed rodent ulcer of the bridge of the nose, invading both upper eyelids, with much subcutaneous infiltration and rapid destruction of tissue. The rodent ulcer in this case is surrounded by a zone of inflammation in the subcutaneous tissue, and the extent of this makes me fear that the introduction of the zinc may lead to the loss of more tissue, and that it will need very long applications to obtain a penetration of the zinc to a sufficient depth. In view of the gravity of this patient's situation, and the failure of radium to improve it, I am at present making use of half-hour applications, but am not yet able to forecast the probable result. In general, my experience has been with small and early cases of rodent ulcer, and I have not yet sufficient experience of the treatment of extensive, spreading, ulcerated cases.

It is not only in my hands that the treatment of rodent ulcer by zinc ions has proved successful. Dr. David Arthur has recorded ${ }^{2}$ four cases which he has treated by this method. Two out of the four healed after one application in fourteen days. The third had two applications, and was also successful. The fourth was described by the writer as doubtful, because, though healed, it appeared unsatisfactory.

Dr. H. P. Tayler has described ${ }^{3}$ the treatment of a rodent ulcer measuring more than one inch in length and half an inch in width. Under the zinc treatment-which was much interfered with by various domestic difficulties - the ulcer was reduced very much in size, so that the cure was nearly complete at the time of the writing of the paper.

Leaving the subject of rodent ulcer at this point I should like to go a step further, by saying that $I$ think that this instance of electrolytic medication is really only the beginning of what may prove to be a series of successes in the treatment of disease by electric currents. One can think of numerous conditions for which some such treatment as the introduction of a drug locally and thoroughly might be efficacious, as, for example, the treatment of ringworm by the introduction of some parasiticide. I have made a few experiments in this affection, and have found that the introduction of copper ions into the ringworm patch may be followed by the disappearance of the fungus and the regrowth of healthy hair.

The effect of zinc upon pustular eczema is very suggestive. In a case supposed to be lupus, which turned out to be one of pustular eczema, the patient had two patches of disease upon the face. One of these was treated by zinc and the other not, and at the end of a week the one treated had gone, while the one untreated remained as before. The second patch was then treated, and it also vanished in the course of a week. So also the introduction of magnesium ions from a magnesium sulphate solution has had a startling effect on three cases of multiple warts in which I have used it, and has caused their prompt disappearance. It is, possible, too, that we may be able by the introduction of some suitable drug to cure lupus. That is a thing 
which I would greatly like to see accomplished. I have been working at the matter for nearly two years, but hitherto, I am sorry to say, without any great success. One would expect that lupus might be readily amenable to some form of electrolytic treatment, but the tubercle bacillus contains from 40 to 50 per cent. of fat, and is probably rendered a non-conductor of electricity thereby; possibly the want of success in my attempts on lupus may be due to this fact. Still, by using such compounds as aniline and its derivatives, it may be hoped that better results may be achieved, and I have already succeeded in arresting the disease in a few slight instances by introducing aniline ions from a solution of the hydrochlorate, though I have failed in many others. Nevertheless, I still consider that the electrolytic method of treating lupus is one which deserves careful study from any one who is willing to devote much time and patience to the task.

1 Archives d'Electricite Médicale, 1903, p. $734 . \quad 2$ Medical Electrology and Radiology, August, 1906. 3 Ibid.

\section{A (Cliniral Serture}

\section{A CASE OF SECONDARY SUTURE OF THE GREAT SCIATIC NERVE.}

\section{Drlivered at the London Hospital.}

BY JAMES SHERREN, F.R.C.S.ENG.,

ASSISTANT SURGEON TO THE LONDON HOSPITAL; SURGEON TO THE POPLAR HOSPITAL FOR ACCIDENTS : ERASMUS WILSON

LECTURER, ROYAL COLLEGE OF SURGEONS.

Examples of complete division of the great sciatic nerve veritied by operation are rare. Excluding the case I am bringing before you this afternoon, I have had the opportunity of examining 11 patients in whom the nerve was injured, but in only one of these was the nerve lesion $\mathrm{de}$. monstrated b.y operation. This patient suffered division of his great sciatic nerve in a stab wound of the middle third of the thigh, but he did not come under my obser. vation early enough to be of use in dete $\mathrm{r}$ m i ning with the necessary exactitude the loss of sens i b i lit $y$ which results from this lesion. When I first $\mathrm{saw}$ him sensibility to prick had obviously begun to be res tored, but the loss of sensibility to light touch was

[Figs. 1, 2, 3, 4, and 5 show the loss of sensibility produced by division of the great sciatic nerve. Within the area bounded by the thick line all forms of sensibility were absent. Within the area between the thick line and the crosses deep touch was appreciated and localized, but there was
loss of protopathic and cpicritic sensibility. Within the area bounded by the crosses and the thin line, epicritic sensibility only was absent.l

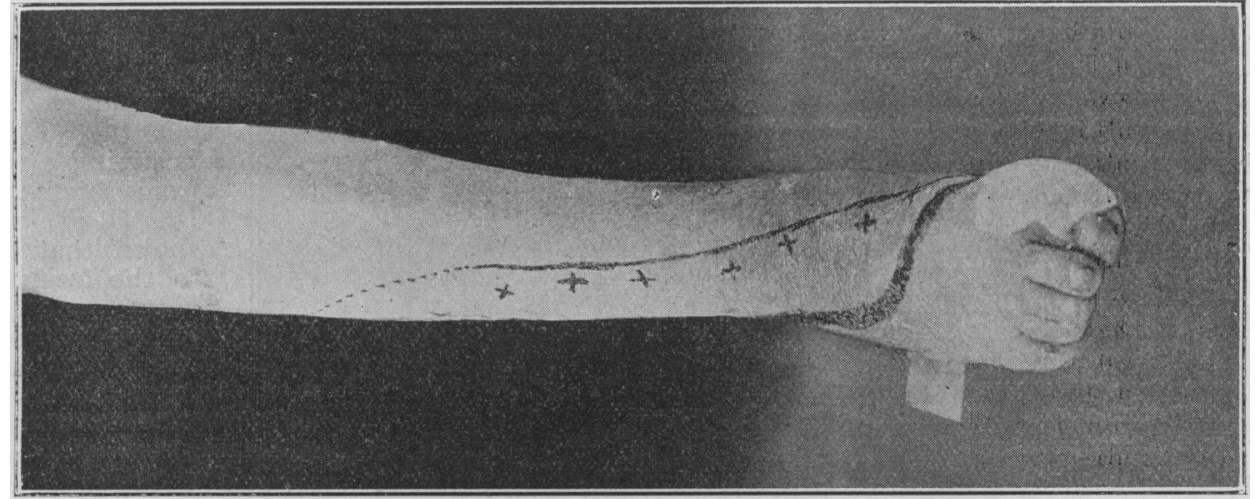

Fig. 1.

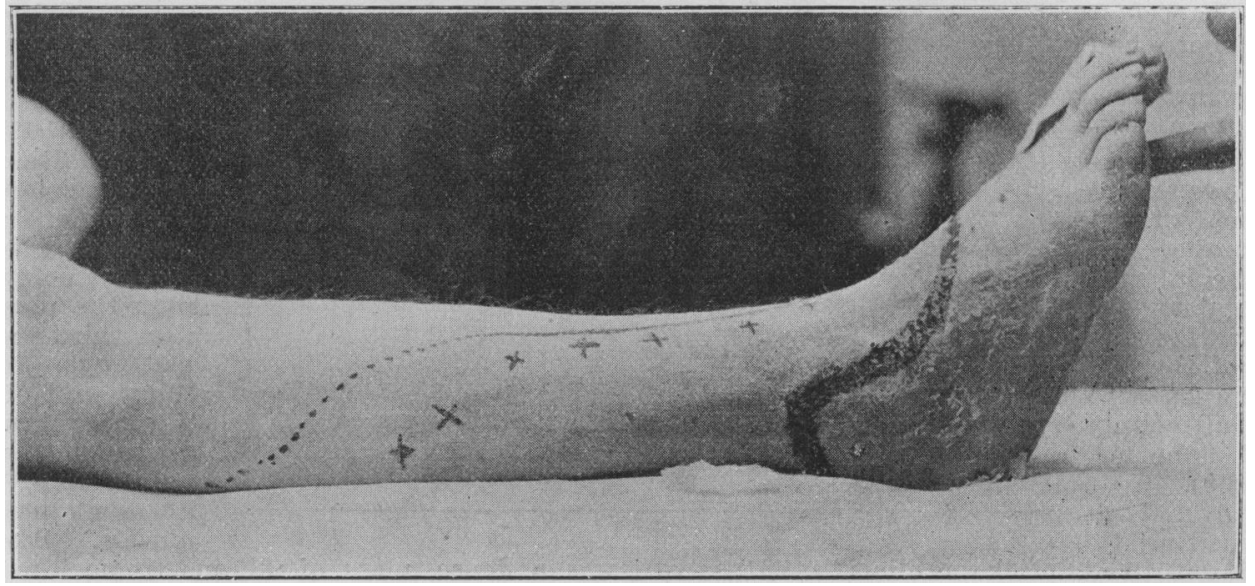

Fig. 2. as extensive anc Mowing you.

Many cases of injury to the great sciatic nerve have been recorded from time to time, but only one with any degree of accuracy-that worked out by Professor C. S. Sherrington. ${ }^{1}$ The present case is therefore of considerable interest; it is the first in which it has been possible to map out the area supplied by the great sciatic nerve exclusively with the three forms of sensibility described by Dr. Head and mygelf. ${ }^{2}$ The small sciatic was also severed; this is the only instance of division of this nerve, verified by operation, that I have been able to find. The history is as follows. :

On October 4th, 1901, while on water picket at Witklip. the patient was ambushed, and shot from 20 yards. The bullet passed through the back of the saddle, and entere just above the fold of the nates. He experienced great pain down the back of the leg into the foot, but rode for 20 yards, when his horse stumbled and he fell off, his right foot being usejess. He lay where he fell for half an hour, then the wound was dressed, and he was taken to Leidenberg Hospital.

I saw him first with Dr. Head at the Royal Victoris Hospital, Netley, on August 2nd, 1902. The wound of entry.was situated $1 \mathrm{in}$. to the right of the spine of the third piece of the eacrum, it was depressed, adherent to bone, and healed with the exception of a small sinus at it centre. One and a half inches in front of the great trochanter was a healed surgi c a w o u n d, t h r o u g which the bullet had been extracted. Midway between these two wounds was an incision diocharging pus, made for the purpose of evacuating an abscess. Into the phy sical signs that were present at that time $I$ do not propose to enter, but will only say that so far as the loss of gensihility and the motor paralysis was concerned they corresponded to those present when he came under my care in April, 1906, three years and nine months later.-

He left Netley in November, 1902, and went to work in September of the next year as plate cleaner in an hotel. He managed to perform his duties satisfactorily until six months before I saw him, when "sores" broke out on the heel and great toe. For these he put himself under'my care. All wounds had healed before he leit Netley. The muscles of the right leg, thigh, and buttock were wasted, 